\title{
NAFTA y CAFTA-DR y su influencia en la democracia y soberanía de sus países parte ${ }^{1}$
}

\section{NAFTA and CAFTA-DR ant their Influence on Democracy and Sovereignty of the Countries Part of those Treaties}

\author{
Asier Tapia Gutiérrez ${ }^{2}$ \\ Unicolombo (Colombia) \\ ORCID: https://orcid.org/0000-0002-4785-4367
}

Recibido: 26-03-2020

Aceptado: 21-10-2020

\section{Resumen}

El presente artículo es un producto de investigación que realiza un análisis del proceso de elaboración y ratificación del NAFTA y CAFTA-DR. El objetivo es conocer cuál es la influencia que todo este proceso alrededor de esos Tratados tiene en la democracia y la soberanía de los países parte acode al trilema de Rodrik. Este análisis se complementa estudiando la posición y papel que Estados Unidos ejerce sobre el resto de los Estados en cuanto potencia hegemónica.

Palabras-clave: Democracia, soberanía, Libre Comercio, NAFTA, globalización.

\footnotetext{
${ }^{1}$ Parte del proyecto Convocatoria 2017 de Proyectos de $\mathrm{I}+\mathrm{D}+\mathrm{i}$ correspondientes al Programa Estatal de Investigación, Desarrollo e Innovación orientada a los retos de la sociedad, en el marco del Plan Estatal de Investigación Científica y Técnica y de Innovación 2013-2016.

2 (atapia@unicolombo.edu.co) Profesor investigador Unicolombo. Abogado Universidad de Deusto, Máster en Relaciones Internacionales Universidad del País Vasco, Máster en Cuestiones Contemporáneas de Derechos Humanos Universidad Pablo de Olavide. Algunas de sus publicaciones son: "NAFTA: Un TLC de características" sui generis" en García Guerrero José Luis (Dir.) y Martínez Alarcón María Luz (Dir.), Constitucionalizando la globalización, Tirant lo Blanch, 2019. pp. 301331; "El eurocentrismo y su afectación a las competencias jurídicas de las comunidades étnicas en Colombia" Revista Análisis Político de la Universidad Nacional, n 95 y "La situación de los Defensores de Derechos Humanos en Colombia", en Cuaderno Deusto de Derechos Humanos $\mathrm{n}^{\circ} 82$ Instituto de Derechos Humanos Universidad de Deusto.
} 


\begin{abstract}
This article is a research product that analyses the process of elaboration and ratification of NAFTA and CAFTA-DR. The objective is to know what is the influence that all this process around these Treaties has had on democracy and the sovereignty of the countries that are part of them, according to the Rodrik Trilemma. This analysis is complemented by studying the position and role that the United States exercises over the rest of the States as a hegemonic power.
\end{abstract}

Keywords: Democracy, sovereignty, Free Trade, NAFTA, globalization.

\title{
Introducción
}

El presente artículo analiza de qué manera el NAFTA y el CAFTA pueden haber afectado el principio democrático de sus países parte con el fin de mejorar los procesos de futuros Tratados para el fortalecimiento democrático y soberano. Se destaca la oportunidad del estudio en una coyuntura global de cambio con un creciente proteccionismo a raíz de la presidencia de Donald Trump, que ha finiquitado o al menos frenado, las progresivas liberalizaciones comerciales provenientes de la década de los ochenta.

A este fin, el trabajo se sustenta sobre el trilema de Rodrik y la relación de impulso y/o limitación entre la Democracia, la Soberanía y los Tratados de Libre Comercio en cuanto ejemplo paradigmático de la hiper-globalización. Para alcanzar el objetivo señalado, tras realizar un breve marco teórico sobre la relación entre la democracia, la globalización y la integración comercial, se analiza cómo ha sido el proceso de negociación del NAFTA y el CAFTA-DR. Previamente se expone el papel decisivo de Estados Unidos en cuanto potencia hegemónica partícipe e impulsora de estos y el Fast Track en tanto instrumento de negociación de Acuerdos utilizado para las negociaciones de numerosos Tratados Comerciales por este país. Conocer este instrumento colabora decisivamente en dos sentidos, por un lado, para conocer de qué manera la esencia del Fast Track afecta a la democracia estadounidense, y, por otro, analizar cómo este mecanismo establece una situación de poder para Estados Unidos respecto de sus contrapartes, incidiendo con ello negativamente en el ejercicio soberano y democrático de estos países.

En los dos capítulos restantes se conocerá cuál ha sido el proceso de negociación en cada uno de los Tratados referidos. Se estudiará no sólo la participación de los tres poderes del Estado, sino también qué grado de participación tiene una sociedad civil en ocasiones discrepante o temerosa de su contenido, así como la situación de poder antes y durante la negociación 
entre los diversos participantes y su reflejo en las negociaciones. Todo ello otorgará una perspectiva completa de cuál es el influjo de estos Tratados en cuanto dispositivos de la globalización en la democracia y la soberanía de estos Estados permitiendo alcanzar conclusiones fundadas en el Trilema de Rodrik.

\section{Democracia, globalización e integración comercial}

La variedad de conceptos definitorios del proceso de globalización y sus diferentes facetas, motivaciones, causas y consecuencias, han estado y permanecen estando en permanente discusión durante las últimas décadas. Es motivo habitual de estas discusiones aclarar y conocer, cuál ha sido, es y debe ser el papel del Estado en ese proceso. Eso supone desentrañar cuáles son las capacidades y mejores métodos de respuesta y adaptación del Estado ante el reto que el proceso de globalización supone para la Democracia y las Soberanías Nacionales.

El Estado tiene el deber y la necesidad de actuar en ejercicio de su soberanía no sólo desde una perspectiva institucional nacional, sino también internacional, dado que la globalización ha superado los escenarios nacionales tradicionales conformándose esencialmente desde el espacio supranacional, donde se ejerce la gobernanza. Con el fin de clarificar el ejercicio de gobernanza en la globalización, la academia ha construido la división conceptual del denominado gobierno interno y externo de la globalización. El primero analiza el ejercicio que los poderes del Estado llevan a cabo para acordar y decidir los intereses de éste y a partir de ahí trasladarlos a las instituciones internacionales, mientras que el segundo estudia la toma de decisiones y posterior actuación al interior de esa institucionalidad internacional en ejercicio del proceso globalizador.

El poder en el proceso de globalización se encuentra y se ejerce desde una multitud de espacios diversos sin una dirección centralizada, sino con una coordinación entre la suma de dispositivos ${ }^{3}$ que lo conforman en aras de lograr el funcionamiento conexo de ese gran sistema de Desarrollo sometido al objetivo de un crecimiento económico permanente. La norma jurídico-política que agrupa y conecta ese caudal de leyes, instituciones, actores, mecanismos y acervo espiritual, algunos autores la han denominado Nueva Lex Mercatoria (Hernández y Ramiro, 2015) y supone la muestra más clara del sometimiento de los Estados y la democracia a los intereses de particulares (Habermas, 2000) y el sometimiento ciudadano al sistema.

\footnotetext{
3 Organizaciones empresariales, mecanismos de arbitraje, entes públicos, organismos internacionales entre muchos dispositivos capilares que constituyen esa Nueva Lex Mercatoria. 
Es destacable cómo la globalización, en cuanto proceso multidimensional, fuerza a los Estados a participar en procesos de integración comercial so pena de quedar aislados del comercio internacional y por ende de toda la institucionalidad internacional que alimenta y guía ese proceso. A raíz de esa inmersión institucional, las prerrogativas democráticas del Estado se ven reducidas fruto de "la cesión de competencias propias a entes supranacionales en los que los ciudadanos no están nada representados (OMC, OTAN, OCDE, etc)" (Goig, 2019, 1236). Supone un alejamiento del demos respecto de los órganos decisorios de materias que les afectan profundamente a sus proyectos de vida. La cesión de soberanías estatales, inherente a cualquier fortalecimiento de entes supranacionales ${ }^{4}$ en términos ejecutivos, junto a la coerción capilar que estas mismas instituciones ejercen sobre las competencias estatales, limitan de forma determinante la capacidad de los Estados para actuar desde la esfera nacional; ello se complementa con la ausencia de una gobernanza internacional que permita controlar democráticamente el proceso de globalización, derivando todo ello en una competencia impenitente entre Estados por unas inversiones limitadas y un pedazo del mercado comercial, sin las capacidades ni las competencias suficientes para hacer frente al marasmo de actores e instituciones que participan de este proceso, viéndose abocados a reducir la exigibilidad en todas las ramas del derecho: laboral, medioambiental, etc.

Si bien es cierto que los Estados al formar parte de un acuerdo de integración comercial lo hacen en ejercicio de sus competencias soberanas, lo llevan a cabo en cuanto entes inmersos en un modelo de Desarrollo Neoliberal en el que han de competir por un nicho reducido de mercado e inversiones del que si se quedaran fuera sobrevendría un estancamiento económico, excepción hecha de aquellos países con bienes primarios escasos con alta demanda internacional y difícilmente sustituibles en un periodo corto de tiempo. A menudo, al interior de los Estados, la ciudadanía no comprende esta "necesidad" de la integración comercial o no comparte la creencia generalizada de que las consecuencias de la inserción en el sistema comercial global son positivas para su Estado y/o sus ciudadanos ${ }^{5}$, motivando oposición y la controversia de hasta qué punto la democracia da respuesta a sus inquietudes y tiene la capacidad de responder a las mismas. Por ello, entre otros asuntos, en el presente trabajo se analizará la influencia ciudadana en la toma de decisiones políticas en la negociación de los Tratados comerciales seleccionados, en cuanto muestra de calidad democrática.

De este modo, la necesaria inserción comercial para la integración en

\footnotetext{
${ }^{4}$ Esta expresión va referida a todo ente supranacional comprendiendo esta última palabra acorde al significado de la RAE "Dicho de una entidad: Que está por encima del ámbito de los Gobiernos e instituciones nacionales y que actúa con independencia de ellos".

${ }^{5}$ Es digno de destacarse en este sentido la confrontación entre aquellos que apoyan los beneficios inherentemente buenos del Libre Comercio y aquellos que lo desechan fundado en consecuencias negativas.
} 
el proceso global a menudo confronta la soberanía y la democracia de los Estados, tal y como detalla Dani Rodrik en su famoso trilema y su "paradoja de la globalización", donde reza categóricamente: "no podemos perseguir simultáneamente democracia, autodeterminación comercial y globalización económica" (Rodrik, 2011, 20). Sostiene que sólo dos de esos tres componentes se podrán ver fortalecidos o defendidos simultáneamente, so pena del menoscabo para el tercero sea cual fuere. Ante ese trilema y la necesidad de optar entre los tres componentes, autores como José Luis Guerrero diferencian entre el gobierno interno y externo como modos de gobernar la globalización. El primero de ellos es referido a la posición que ejercen los Estados mediante los tres poderes en la negociación y firma de integraciones comerciales y en su gobierno interno, asunto que variará en función del tipo de integración: Zona de libre Comercio, Unión Aduanera Mercado Común y Unidad Económica y monetaria supraestatal (Guerrero, 2019a, 104 y siguientes).

Resulta pertinente estudiar el modo en que los Estados y sus poderes responden ante una doble presión interna soportada en su afán desarrollista de impulsar el crecimiento económico y el bienestar de unos ciudadanos, y externa desde unas instituciones internacionales que coartan la capacidad ejecutiva del propio Estado derivado de la cesión de competencias a diversas instituciones y la superación de las capacidades de éste para influir o controlar la unidad de un mercado que ha superado el ámbito nacional. Ello motiva a conocer de qué manera estos poderes del Estado responden a las exigencias y reivindicaciones de sus ciudadanos.

La posición de los Estados en términos de poder y capacidad para ejercer sus competencias soberanas y ver las mismas limitadas a raíz de la inclusión en un acuerdo de Libre Comercio no solo depende del tipo de integración del que se trate, sino de otra suerte de factores como puede ser el tamaño y potencia económica de los diversos países participantes, así como la propia postura que adoptan los poderes del Estado en relación con el mismo acuerdo comercial, tal y como distingue el profesor Guerrero en la Unión Europa entre Alemania y países periféricos como España, Italia y Portugal (Guerrero, 2019b, 1353). Ello se muestra fehacientemente en la posición directora de Estados Unidos en la elaboración de los Acuerdos objeto de estudio de este trabajo: NAFTA y CAFTA. El influjo ejercido por Estados Unidos a los países parte de esos Tratados será decisivo en la afectación al principio democrático de esos países junto a la atracción ideológica que en sus élites gobernantes ejerció el Neoliberalismo y la globalización en cuanto "nueva razón del Mundo" (Laval y Dardot, 2013). 


\section{Estados Unidos y Fast Track: Entre la pérdida democrática y el mantenimiento de la hegemonía}

El Fast Track es un controvertido procedimiento legislativo abreviado inserto en el ordenamiento jurídico norteamericano que otorga al presidente de Estados Unidos la autoridad de negociar y someter a la aprobación de las cámaras legislativas estadounidenses un Tratado internacional sin el procedimiento habitual de elaboración legislativa con las consiguientes modificaciones, fiscalizaciones y enmiendas parte de ese proceso en su procedimiento habitual. La aprobación del Tratado en cuestión es una suerte de susto o muerte a la totalidad de este, tal y como es presentado para su aprobación, quedando las cámaras legislativas ante la tesitura de desechar todo el proceso de negociación que ha resultado en el Tratado o aprobarlo de forma completa. Este proceso suscita dudas de su connivencia para con el respeto del principio democrático en Estados Unidos de forma directa, así como de forma indirecta para con el principio democrático de los otros países que forman parte de una negociación comercial con el anterior.

Esta institución y su procedimiento arrastran la duda de hasta qué punto la posibilidad de obviar el procedimiento legislativo común es una limitación de la democracia legalizada acorde al propio cauce democrático y si de ello se derivan posibles inconstitucionalidades, circunstancia que ha motivado que algunos autores la denominen como un "Caballo de Troya muy elegante y moderno" (Tucker y Wallach, 2009, 3). La crítica sobre su afectación al principio democrático descansa fundamentalmente sobre la imposibilidad de modificar el contenido de la propuesta de Tratado en aras de su aprobación y la objeción sobre la nula rendición de cuentas a lo largo del proceso. La primera es respondida por los defensores de este procedimiento mediante diversas posiciones, siendo quizás la más consolidada el hecho de que el Fast Track es un mecanismos establecido autónomamente por el Congreso (Hongju Koh, 1992, 164) en cuanto parte de su ejercicio democrático y por ello no es antidemocrática, argumentación insuficiente si tenemos en cuenta que incluso en la antigua Roma, el ordenamiento jurídico de la época permitía al Senado, mediante la figura del Senatus Consultum Ultimum la elección de una figura dictatorial como emergencia para salvar la República, autoexcluyendo sus competencias legislativas. No obstante, el problema de fondo respecto del Fast Track no es si es o no antidemocrático, sino si hay una limitación auto-inducida de la democracia y por ello debe ser respetada, ya que como afirma el profesor Harold Hongju Koh:

En la base, no se está reclamando que el proceso del Fast Track sea antidemocrático, sino que su uso tiende a otorgar al presidente mayor ventaja e influencia sobre la sustancia de los procesos de negociación comercial que hubiera tenido bajo los procedimientos ordinarios Hongju Koh, 1992, 170). 
Es evidente que con esta institución se limitan las capacidades democráticas de las cámaras estadounidenses, asunto que se pone de manifiesto cuando en el resto de argumentación en su descargo de diversos autores, mayoritariamente se fundan en:

1. matizar su afectación a la democracia,

2. defenderla desde posiciones ideológicas,

3. sostener su necesidad estratégica de ampliar el proceso de liberalización comercial para la que el Fast Track ha sido fuente necesaria (Wagner, 2000, 1056).

La defensa de la limitación de los poderes democráticos por parte del Fast Track bajo criterios de interés o estratégico, motiva a cuestionarse cuáles son tales criterios y qué nos indica su priorización a costa de limitar la democracia. Si se toma en cuenta que Estados Unidos ha sido uno de los países que con más énfasis ha promovido desde hace décadas la apertura de fronteras a bienes, servicios y capitales a nivel global y que desde hace décadas es el país que lidera la hegemonía liberal, se puede afirmar que la limitación democrática auto-establecida es uno de los precios que este país asume que debe pagar para el sostenimiento de su poder hegemónico. Se manifiesta con ello un avance más allá del referido Trilema de Rodrick, dado que USA no sólo acepta y adopta en pleno ejercicio democrático una limitación de esta para su integración comercial, sino que lo hace con el objeto de establecer un régimen comercial acorde a sus intereses, que con el procedimiento legislativo habitual pudiera verse debilitado o no tan fortalecido. Esta posición la puede ejercer en exclusiva Estados Unidos por su posición de liderazgo hegemónico, motivo por el que es probablemente el único país que adopta un instrumento de negociación de este tipo. La necesidad estratégica referida no es otra cosa, por tanto, que la posición de superioridad en la negociación que este mecanismo otorga a Estados Unidos, con la consiguiente afectación al principio democrático de los otros Estados.

De la simple existencia de este mecanismo se deduce, por un lado, que Estados Unidos es el guía que marca el camino en las negociaciones de comercio que promueve y participa, con la consiguiente posición subordinada para con la democracia del resto de países, y, por otro, que a la mejor posición negociadora del presidente de Estados Unidos derivado del propio Fast Track, se adiciona que a diferencia de otros países no debe atender a los otros poderes del Estado hasta finalizar la negociación, en una omisión democrática para un pretendido fortalecimiento soberano. 


\section{NAFTA: Negociación, acuerdo y afectación al principio democrático}

Si bien del capítulo precedente pudiera presumirse un liderazgo unilateral y absoluto con trazos imperiales por parte de Estados Unidos, de lo observado por diversos autores a lo largo de todo el proceso de negociación y aprobación hasta la firma del NAFTA, así como de los hechos acaecidos al interior de México y Canadá la década que antecedió al Tratado, se asume una situación sustancialmente diferente, tal y como se expone a continuación.

Es patente y manifiesto que, durante la década previa al NAFTA, el gobierno mexicano llevó un proceso de apertura económica desde una economía sustancialmente proteccionista fundada en el paradigma de sustitución de importaciones hacia una más abierta y liberal, presumiblemente con el objeto de formar parte del naciente proceso de integración comercial en el periodo post guerra fría ${ }^{6}$. En el mismo ejercicio de gobierno previo a la negociación del NAFTA, México, además de la aprobación del Tratado que nos ocupa y como parte de ese mismo proceso liberalizador y de inserción comercial se unió al GATT y la OCDE. Difícilmente se puede afirmar que este proceso de reforma mexicano sea resultado directo de una presión ejercida por el gigante estadounidense y por ende una afectación a su principio democrático ${ }^{7}$. El proceso liberalizador mexicano dimana más bien de la presión soportada desde dos esferas:

-Una crisis económica nacional a la que se responde con políticas neoliberales, haciendo buenos los postulados de Rodrik que afirma que ese tipo de políticas se llevan a cabo cuando las condiciones económicas son desfavorables y las políticas previas parecen no funcionar (Rodrik, 1996, 20).

-Un proceso internacional de integración comercial creciente del que el presidente Salinas de Gortari quería formar parte ante la conyuntura de la creciente integración por parte de diversos países europeos, así como americanos, tal y como se evidencia con la firma del Tratado entre Canadá y Estados Unidos (Long, 2014). La posición de Salinas de Gortari, pese a las afirmaciones de su futuro negociador del NAFTA Jaime Serra Puche unos meses antes que afirmaba que no era pertinente la negociación por la posición de inferioridad de México en la misma, manifiesta la decisión soberana mexicana de ser partícipe del proceso de inserción comercial global: "Nuestros argumentos a favor eran claros (sobre el NAFTA): Hemos abierto nuestros mercados unilateralmente

${ }^{6}$ Dani Rodrik en Rodrik 2011 defiende que a la postura discursivamente consensuada de que la liberalización fue una obligación derivada de la escasez de crecimiento del modelo se contraponen unos resultados de ese proceso que muestran muchas dudas de que esta apertura fuera un acierto en términos económicos.

7 Asunto que se escapa a las posibilidades de este trabajo es dilucidar si la democracia mexicana está o no parcial o totalmente cooptada por unas elites insensibles a las necesidades y requerimientos del pueblo y cuál haya podido ser la influencia de Estados Unidos en esta situación. 
desde mediados de 1980 y ahora queríamos reciprocidad; los bloques comerciales se estaban formando y no queríamos quedar aislados" (Salinas, 1990). Salinas de Gortari era un miembro más de los conocidos en México como Tecnopols, gente educada en Estados Unidos que ocuparon altos cargos del gobierno económico mexicano y eran claramente proclives a la apertura comercial y a posiciones neoliberales en lo que podría observarse desde una posición foucaltiana como una imposición de políticas a través de la creación de saber y su establecimiento como verdad para simultáneamente influir en decisiones al más alto nivel político (Foucault, 1980).

En la afirmación de Gortari se observa una clara perentoriedad hacia la participación en el proceso de integración global ante el temor de llegar tarde o quedar excluido. La presión no es tanto de Estados Unidos, sino de un sistema internacional que comenzaba a fraguarse, del que sin duda el gigante norteamericano fue bastión de su impulso, pero no exclusivo. Adicionalmente, la ratificación del Acuerdo Comercial entre Estados Unidos y Canadá aceleró la "necesidad" de negociar el NAFTA, especialmente cuando en su visita a Europa el presidente mexicano vio que este continente no miraba tanto hacia América como hacia los recientemente liberalizados países del Este. Algunos autores obvian la influencia sistémica externa, y la apropiación de las élites políticas mexicanas del poder, atribuyendo todo el proceso del NAFTA y su precedente CUFTA a Estados Unidos, fundando sus posiciones en la afirmación de Ronald Reagan de estos Tratados como "Una nueva Constitución para América del Norte" (Alimonda, 1994, 93).

*

El proceso de negociación del NAFTA no fue arduo. En el caso de México, acorde a las tesis de Mauricio Lascurain, este país había llevado a cabo buena parte de las concesiones necesarias en el proceso de liberalización previo, a fin de evitar conflictividad interna (Lascurain, 2009, 98). México, por su posición de dependencia económica, fue quien debió conceder más en la negociación. Debido a ello, su gobierno "tuvo que crear alianzas estratégicas con los diferentes sectores empresariales y laborales, a fin de poder implementar las reformas de mercado, que, por su naturaleza, generaría ganadores y perdedores" (Lascurain, $2009,99)$ lo que no es sino un cierto elogio a su dialogo democrático, pese a ser de protección preventiva.

El proceso de Canadá guarda ciertas similitudes con México. Pese a tener una economía más abierta que la mexicana, no lo era tanto en comparación con USA y se caracterizaba por un Estado de bienestar más semejante al modelo europeo. Con el cambio de gobierno de Trudeau a Mulroney, este decidió adoptar el modelo neoliberal de mercado estableciendo un acuerdo para negociar en 1985 el futuro Acuerdo Comercial CUFSTA con Estados Unidos. Tal como expone el profesor Héctor Alimonda: "Estas negociaciones 
tuvieron un carácter reservado, con muy poca información difundida, y sin que la ciudadanía tuviera capacidad alguna de intervención". (Alimonda, 1994, 90 y 91). Es decir, manifiestamente carentes de condiciones democracias.

Poco después, Canadá comenzó a negociar el NAFTA, con el objetivo fundamental de no ver perjudicados los privilegios obtenidos de Estados Unidos en su acuerdo comercial aprobado unos años antes (Tapia, 2019, 304). En este caso, Canadá, tal y como expuso detalladamente en su trabajo Stéphane Paquin, dio gran prevalencia a las provincias canadienses en la negociación del acuerdo mediante la participación de sus gobiernos, un hito histórico en el momento (Velázquez, Fry y Paquin, 2014) que Early Fry ya solicitaba a partir de la firma del anterior Tratado (Fry, 1994). Sin duda, esta participación federal incidió en una mayor transparencia hacia la ciudadanía que en las diversas provincias pudo hacer mayor seguimiento y fiscalización del proceso negociador en clara contraposición a la opacidad del precedente. Esta innovación canadiense supuso una creciente participación de estos gobiernos provinciales en la implementación de sucesivos Tratados internacionales, reservándose el gobierno federal la negociación, firma y ratificación (Paquin, 2010), amparado en varias instancias judiciales (Zepeda y Virchez, 2019, 92).

La participación tanto de los poderes legislativos como judiciales de los países parte de este Tratado fue prácticamente intrascendente, asumiendo los ejecutivos tanto el procedimiento como el contenido. Esto puede ser debido a que eran parte de un proceso coyuntural y sustancialmente innovador en ese momento y también a las características particulares de cada uno de los Estados como pueda ser el Fast Track Estados Unidos, o la mayoría parlamentaria del PRI en México.

\section{CAFTA/DR: Negociación, acuerdo y afectación al principio democrático}

Es destacable cómo, análogamente a lo ocurrido en el caso del NAFTA, los países centroamericanos llevaron a cabo un proceso autónomo de apertura comercial durante la década de los ochenta, por las mismas causas y con objetivos equivalentes al mexicano. (sobre Guatemala Maul, Bolaños y Díaz, $2007,9)$. Valga por tanto para el asunto lo precedente en lo concurrente en lo que a términos argumentativos expresa de la apropiación de las elites políticas centroamericanas de las bondades del discurso Neoliberal.

Más allá de cierta controversia o inexistencia de consenso respecto de quien alentó la negociación para este Acuerdo Comercial, Estados Unidos, tal y como observamos en el precedente del NAFTA, no tiene necesidad de realizar 
presión directa sobre los países, debido a que con el impulso sistémico directriz hacia la institucionalidad internacional y la propia autonomía expansiva de esta, numerosos países se ven abocados a ello. De hecho, autores como Anabel González, negociadora por Costa Rica del CAFTA-DR, exponen cómo el NAFTA aceleró el deseo de Centroamérica de negociar un Tratado "de paridad con el TLCAN (NAFTA en inglés)" (González, 2006, 3) por el miedo a la afectación que pudiera sufrir la región por los beneficios hacia el sector textil y de confección mexicano otorgado por el primero de los Tratados.

Una circunstancia definitoria en el proceso de negociación es la dependencia exportadora de la gran mayoría de países centroamericanos respecto de Estados Unidos, país al que hasta el año 2001 se dirigía casi la mitad del comercio de la región, más del doble que al resto de países centroamericanos en cuanto segundo destinatario comercial centroamericano. La región recibe de Estados Unidos casi un $42 \%$ de sus importaciones frente al $14.5 \%$ de los países centroamericanos restantes. Por el contrario, para Estados Unidos apenas el $0.97 \%$ de sus importaciones total provienen de la región, frente al $1,2 \%$ de sus exportaciones (SIECA, 2002), algo en términos globales poco significativo y muestra de la asimetría en términos de dependencia. No obstante, la balanza comercial es desde 1996 favorable a Centroamérica, con un aumento desde 1993 hasta 2001 del $485 \%$ frente al aumento de $255 \%$ de las importaciones (Bake y Spross, 2002, 10). Otro aspecto reseñable que da buena cuenta de la asimetría de poder y dependencia entre el istmo y el gigante norteamericano es el PIB per cápita estadounidense, que ya en 2001 era casi $36000 \$$ frente a los $1885 \$$ de media en Centroamérica, con las marcadas diferencias internas incluso entre Costa Rica con $4013 \$$ frente a los $499 \$$ de Nicaragua (SIECA 2002), como país con el PIB per cápita más elevado y más bajo respectivamente. Otra muestra de la dependencia económica de Centroamérica, que se acentuaría con la entrada en vigor del CAFTA-DR, lo supone la deuda de la región, que subió progresivamente entre 1999-2003 a excepción del año 2000 en Honduras y que, acorde a cifras de la CEPAL, en todos los países, a excepción de Costa Rica, la deuda externa es más del bloque que la interna (Moreno, 2014, 114 y siguientes).

La integración comercial estadounidense con Centroamérica se alentó mediante la Ley de Recuperación Económica de la Cuenca del Caribe (ICC) de 1983 y la posterior Ley de Asociación Comercial con la Cuenca del Caribe que permitió a partir del año 2000 el desarrollo y la exportación de productos textiles de estos países a Estados Unidos. Fue una ley discursivamente promulgada con el fin de mitigar el daño que había provocado y podía seguir provocando el NAFTA, tal y como señalamos arriba. El problema, tal y como exponen para un estudio de la CEPAL Amparo Pacheco y Federico Valerio, es que:" a pesar de que estas leyes han beneficiado a los países de la región por muchos años, 
tienen limitaciones inherentes a su carácter unilateral y temporal" (Pacheco y Valerio, 2007, 12). Esto es, no es un mecanismo de ayuda, sino un instrumento al servicio de la política estadounidense para controlar estos países, coartando sus democracias y soberanías mediante la generación de dependencia.

Otra de las cuestiones que caracterizan la negociación del CAFTA/DR es que, desde un comienzo, la misma se divide en dos partes negociadoras, más la postrera inclusión de una República Dominicana interesada desde un comienzo: USA y Centroamérica. El hecho de que Centroamérica vaya unida en la negociación se puede comprender desde un punto de vista pragmático de facilitar un acuerdo sin dilaciones. No obstante, difícilmente se puedan aunar intereses comunes de varios países sin consecuencias en ocasiones nefastas para alguno o varios de ellos y en particular los sectores desfavorecidos de los países más dependientes. Esta circunstancia es especialmente notoria cuando las diferencias económicas e incluso en términos productivos de cada uno de ellos y de la región con el gigante estadounidense son tan exuberantes, sin obviar la experiencia centroamericana de negociar otros Tratados conjuntamente ${ }^{8}$. Este modo de negociación es muestra palmaria de la debilidad y dependencia de todos ellos respecto del acuerdo y la economía estadounidense, mala coyuntura para negociar uno.

A lo largo del proceso hubo un sinfín de pequeñas discrepancias en la negociación de materias, con cada uno de los países centroamericanos abogando por contenidos que favorecieron a su respectivo país ${ }^{9}$. En la cuarta ronda de negociaciones se produjo una controversia pública destacable entre los países de istmo hasta el punto de que Nicaragua amenazó con retirarse y firmar un acuerdo bilateral y trascendió una oferta bilateral de ese gobierno a Estados Unidos obviando el proceso negociador (Bravo, Ramos, 2008, 28). En la quinta ronda se repitió cierto enconamiento de las diversas posturas al interior del istmo hasta sopesarse la posibilidad de suspensión de la Ronda negociadora. En este caso discreparon fuertemente Guatemala y el resto de los países en relación con la oferta de desgravación que se trasladaría a Estados Unidos. Afortunadamente, tanto la debilidad negociadora de la región como las discrepancias internas se mitigaron sustancialmente al dotar a Costa Rica de amplias atribuciones y competencias en cuanto secretario del grupo centroamericano y ejercer un liderazgo destacable.

Del modo en que se estableció y se llevó a cabo el proceso de negociación se pueden destacar varias cosas. La escasa participación de los legislativos de los diversos países hizo recaer ese peso sobre los poderes ejecutivos, análogamente a lo ocurrido en el NAFTA. En este sentido se comprende mejor

${ }^{8}$ Había negociado ya conjuntamente un TLC con la Republica Dominicana y otro con Chile, además de otros entre varios de los países del Istmo.

${ }^{9}$ Se puede destacar la menor protección, 50 en lugar de 70 años, a la protección de las obras en El Salvador frente a los 70 del resto de países centroamericanos.

Araucaria. Revista Iberoamericana de Filosofia, Politica, Humanidades y Relaciones Internacionales, año $23, \mathrm{n}^{\circ} 48$. Tercer cuatrimestre de 2021. Pp. 123-139. ISSN 1575-6823 e-ISSN 2340-2199 https://dx.doi.org/10.12795/araucaria.2021.i48.06 
la participación de algunos legisladores en el denominado cuarto adjunto, un dispositivo de contacto, información y consulta, con el fin de facilitar la participación de actores privados (empresas fundamentalmente) en la negociación y los contenidos que les interesen y afecten del Tratado. El poder legislativo queda reducido a leves contactos con sus respectivos gobiernos en el proceso de negociación, la aprobación del Tratado para su inclusión en el ordenamiento interno y la modificación previa o posterior al Tratado de cuantiosa legislación interna, con el fin de evitar posibles controversias entre el Tratado y el ordenamiento jurídica interno. Esta legislación que necesitada ser reformada fue recogida por la CEPAL en un estudio (Pacheco y Valerio, 2007).

El cuarto adjunto, traído de otras negociaciones previas del istmo, facultó la participación de movimientos de la Sociedad Civil ${ }^{10}$. Este mecanismo de participación para la Sociedad Civil acrecienta la transparencia y al menos simbólicamente otorga voz y se escucha a ciudadanos que pudieran no estar satisfechos con estos mecanismos por la causa que fuera. Supone, por tanto, una al menos leve mejora democrática. No obstante, dado el gran nivel de crítica ocasionado por el CAFTA resulta a toda luz insuficiente, obviando mecanismos de ratificación popular exigidos en países como Guatemala (Consulta Popular, 2005) que sí se llevó a cabo en Costa Rica, resultando en un apoyo de apenas el $51 \%$ a favor del Tratado.

Costa Rica fue paradigmático no sólo por la celebración de este referendo, sino también por una Consulta previa a la aprobación a la Sala Constitucional de la Suprema Corte de la nación para elucidar si el Tratado pudiera resultar inconstitucional ante potenciales violaciones de Derechos derivadas de su implementación. La Consulta fue realizada por la Defensoría de los Habitantes y apenas 19 diputados. En uno de los elementos de la Consulta referido a la primacía entre Derecho Internacional y la Constitución, hace bueno los art. 27.1 y 46.1 de la Convención de Viena que impide el incumplimiento de Tratados Internacionales fundado en el ordenamiento interno.

Un elemento decisivo para nuestro interés del voto 9469-07 dicta lo siguiente:

la sala solo puede realizar una función como garante e intérprete de la Constitución Política. Lo relativo a la conveniencia o no de la aprobación, así como los aspectos económicos, que envuelven al Tratado, no son extremos que pueden discutirse en esa vía.

\footnotetext{
${ }^{10}$ Nótese, en referencia a la dificultad de establecimiento de una posición centroamericana en las negociaciones, que, si bien en un comienzo se intentó llevar a cabo un cuarto adjunto de la región, a partir de la segunda ronda de negociaciones hubo un cuarto adjunto nacional y otro regional, para a partir de la sexta ronda eliminar el regional.
} 
La Suprema Corte se aparta de decidir sobre el fondo del asunto al exponer la dificultad de establecer una relación causal entre los preceptos de los Tratados y violaciones constitucionales derivadas del mismo. Queda por tanto la decisión circunscrita al quehacer político, desechando la influencia del poder judicial en la elaboración y contenido de los TLCs. En ese mismo sentido es declarada la constitucionalidad del Tratado, al comprender que este no afecta de tal manera a la soberanía y capacidad ejecutiva del Estado para impedirle actuar en defensa del Derecho a la Salud (considerandos X y XI), protección a los grupos menos desfavorecidos (considerandos XII) y otras materias, tal y como desarrolló profundamente en su capítulo María Martín Sánchez (Sánchez, 2019).

\section{Conclusiones}

La conclusión general en relación con la manera en que los TLCs influyen en el principio democrático estatal es que, si bien el embate de estos instrumentos de la globalización es sustancial, su influjo es compartido por la influencia directa estadounidense junto a la ejercida por el propio proceso de globalización del que estos instrumentos son elementos sine qua non. Tanto es así, que al ser Estados Unidos partícipe de los dos resulta difícil discernir qué se debe y qué no a su pertenencia al proceso, ya que Estados Unidos es, sino el sujeto nuclear de la globalización, un actor sin el cual el proceso hubiera sido sustancialmente diferente.

En el análisis del Fast Track se evidenció cómo este mecanismo limita las soberanías de los Estados parte de los Tratados en que Estados Unidos lo utiliza; este país, como contrapartida de lo anterior y derivado de las mismas características que le conceden una posición de prevalencia en las negociaciones, limita autónomamente el papel de sus órganos legislativos en la fiscalización del proceso negociador y ratificador.

De ninguno de los dos Tratados se puede afirmar que sea producto de coacción, exigencia o imposición estadounidense, sino que, bien al contrario, casi todos los Estados parte comenzaron a liberalizar sus economías autónomamente para evitar quedar aislados del proceso de integración comercial. Ergo son producto de una influencia en sus soberanías por el proceso liberalizador en su fase expansiva, sin omitir que Estados Unidos en cuanto impulsor global ejerce una presión indirecta esperando posteriormente que los países acudan a él en muestra de dependencia.

Del propio proceso de negociación de los Tratados se evidencia, como ya era conocido, que Estados Unidos es el sol alrededor del que gira el resto del sistema interestatal. Por otro lado, la preeminencia de los órganos ejecutivos frente a los legislativos y judiciales en la negociación es manifiesta, siendo 
los segundos insignificantes en términos funcionales. No obstante, sobre el asunto se plasmaron diferencias entre los dos Tratados que sugieren una evolución. En el NAFTA los gobiernos regionales canadienses tuvieron una participación sustancial en un ejercicio de fortalecimiento democrático, mientras México exclusivamente dio pábulo a una élite empresarial moderna que abogaba por la apertura comercial obviando protestas y sabedor de tener las mayorías necesarias en las cámaras para su aprobación. En el caso del CAFTA-RD, es destacable cómo Centroamérica participó como un todo con las consabidas consecuencias coartadoras de sus respectivas soberanías. Asimismo, en este último se estableció el denominado cuarto adjunto para formalizar la posibilidad de que en un principio regionalmente y a la postre nacionalmente, los gobiernos conversaran sobre las materias en negociación con actores privados, a los que también se unieron los miembros de la Sociedad Civil con capacidad para financiarse la estancia en los lugares de negociación. Ello es un avance indiscutible en términos de transparencia y participación de los interesados y conlleva, aun sin capacidad de decisión, un paso adelante por tanto en democratización de los procesos de negociación. Como se expuso, los órganos legislativos, así como las ciudadanías, son poco más que convidados de piedra en la negociación de estos Tratados, siendo encargados de poco más que modificar las leyes internas necesarias para no contravenir su contenido.

Es digno de subrayar, en clave de excepción, cómo Costa Rica antes de ratificar el CAFTA-DR llevó a cabo un referéndum para consultar a su población si quería formar parte de este, así como una consulta a la Suprema Corte sobre la constitucionalidad de su contenido. El hecho de que el país actor de ambas excepciones fuera el mismo, nos hace cuestionarnos si es debido a que tiene una democracia más consolidada y fuerte, lo que de algún modo refrendaría la tesis del Trilema de Rodrik de la necesidad de un fortalecimiento interno antes de cesiones soberanas para integrarse comercialmente o si el motivo de estas acciones pudiera ser debido a que no tenía muchos antecedentes previos de este tipo de Tratados y respectivas negociaciones.

\section{Bibliografía:}

Alimonda, H. "NAFTA blues. La crítica canadiense a los acuerdos de libre comercio en América del Norte" Nueva Sociedad, 1994, no 133, p. 88-101.

Bake, R. M., y Spross, F. "El tratado de libre comercio con los estados unidos: temas sensitivos para centroamerica y recomendaciones para optimizar la negociación", 2002. http://www.hacer.org/pdf/TLC.pdf última visita 22 de septiembre de 2020. 
Bravo, A., y Ramos, K. "El Tratado de Libre Comercio entre Estados Unidos y Centroamérica (CAFTA): descripción y análisis de las rondas de negociación" Iniciativa Mesoamericana de Comercio, Integración y Desarrollo Sostenible; Fundación Nacional para el Desarrollo, 2008.

Foucault, M. “Power/Knowledge”, Pantheon Books, New York, 1980.

Fry, E. " Relaciones económicas internacionales de las provincias de Canadá" Comercio exterior, 1994, vol. 44, no 2, pp. 132-137.

Guerrero, J. L. "Los embates de la globalización a la democracia”, en García Guerrero José Luis (Dir.) y Martínez Alarcón María Luz (Dir.), Constitucionalizando la globalización. Tirant lo Blanch, 2019A. pp. 1335-1372.

Guerrero, J. L. “Constitucionalizando la globalización”, en García Guerrero José Luis (Dir.) y Martínez Alarcón María Luz (Dir.), Constitucionalizando la globalización. Tirant lo Blanch, 2019B. Pp.71-139.

Goig, J. M. "La OCDE en un contexto de globalización. Su influencia en un momento de política económica mundial: el influjo de la OCDE en España”, en García Guerrero José Luis (Dir.) y Martínez Alarcón María Luz (Dir.), Constitucionalizando la globalización. Tirant lo Blanch, 2019. рр. 1233-1289.

González, A." El proceso de negociación de un tratado de libre comercio con Estados Unidos: la experiencia del tratado de libre comercio entre Centroamérica, Estados Unidos y República Dominicana”, BID-INTAL, 2006.

Habermas, J. "El derecho internacional en la transición hacia un escenario posnacional" Katz ed. 2000.

Hernández J. y Ramiro, P. “Contra la lex mercatoria.” Bilbao: Ed. Icaria Más (2015).

Koh, H. "The fast track and United States trade policy" Brook. J. Int'l L. 18, 1992, pp.143-180.

Laval, C. y Dardot, P. “La nueva razón del mundo” Editorial Gedisa, 2013.

Lascurain, M." Tratado de Libre Comercio de América del Norte como impulsor de la globalización económica en México", Tesis Doctoral. Universidad Autónoma de Madrid. Madrid, 2009.

Lizano, E. y González, A. "El tratado de libre comercio entre el istmo centroamericano y los Estados Unidos de América”, Documento de diseminación, 2003.

Long, T." Echoes of 1992: the NAFTA negotiations and North America now", Wilson Center Mexico Institute, diciembre de 2014.

Maul, H., Bolaños, L., \& Díaz, J. “DR-CAFTA un año después: su impacto y recomendaciones para Guatemala”, Guatemala: CIEN, 2007. 
Moreno, R., "El CAFTA-DR y la deuda externa en Centroamérica", La Universidad, (1), 2014, pp-109-137.

Pacheco, A. y Valerio, F. "DR-CAFTA: aspectos relevantes seleccionados del tratado y reformas legales que deben realizar a su entrada en vigor los países de Centroamérica y la República Dominicana” CEPAL, 2007.

Paquin, S. "Federalism and Compliance with International Agreements: Belgium and Canada Compared”, The Hague Journal of Diplomacy vol.5, n (1-2), 2010.pp. 173-197.

Rodrik, D. "Understanding Economic Policy Reform", Journal of Economic Literature, Vol. XXXIV,1996, pp. 9-41.

Rodrik, D.” La paradoja de la globalización" Antoni Bosch Ed. S. A, 2011.

Salinas, C, Carlos Salinas de Gortari en conversación con Robert A. Pastor de 28-07 1990, Papeles personales de Robert A. Pastor https://www. wilsoncenter.org/sites/default/files/media/documents/publication/Long NAFTA and Now.pdf

Sánchez, M. "Tratado de libre comercio de Centroamérica, Estados Unidos y República Dominicana”, en García Guerrero José Luis (dir.) y Martínez Alarcón María Luz (dir.), Constitucionalizando la globalización, Tirant lo Blanch, 2019. Pp.333-369.

Tapia, A. "NAFTA: Un TLC de características" sui generis" en García Guerrero José Luis (Dir.) y Martínez Alarcón María Luz (Dir.), Constitucionalizando la globalización, Tirant lo Blanch, 2019. p. 301-331.

Tucker, T. y Wallach, L. "The Rise and Fall of Fast Track Trade Authority." Washington, DC: Public Citizen, (2009).

Velázquez R. Fry E. y Paquin S." The external relations of local governments in North America after NAFTA: Trends and Perspectives" Universidad Autónoma de Baja California. 2014.

Wagner, C. "Another Attack on the Fast Track.". Louis ULJ 44 (2000): 1047.

Zepeda, R. y Virchez, J. 'The role of subnational actors in North America during the NAFTA renegotiation, en Gavinelli ”, (Ed) Geographical Experiences, Representations and Narratives, vol2. 2019, pp-87-95.

"Consulta popular", exigen en Guatemala antes que ratificación TLC", Prensa Latina 2005, http://www.bilaterals.org/article.php3?id article=1296

Sentencia de la Sala Constitucional de la Suprema Corte de Costa Rica. 200709469 de 3 de julio de 2007.

SIECA "Relaciones Comerciales de Centroamerica y Estados Unidos de América", Secretaría de Integración Económica Centroamericana, Guatemala, 2002, 22 pp. 
